\title{
Benefits of interprofessional education in health care
}

\section{Paul Illingworth, Sonya Chelvanayagam}

\begin{abstract}
This article examines some of the literature regarding the benefits of interprofessional education (IPE) in the field of health care. These benefits in relation to service users (and carers), higher education institutions, service providers and students are all explored. Barriers to IPE are being broken down by many of the various stakeholders working towards a similar agenda. However, currently there remains some doubt as to whether IPE has a direct positive impact on the health gain of service users and carers. Research is needed to demonstrate if service users and carers benefit directly from IPE and if they do not, the reason for pursuing it needs to be questioned.

\section{Introduction}

Although various terms are used and defined, it is important to define what interprofessional education (IPE) is. As a consequence, the author developed the following working definition

'Education occurs mutually between individuals involved in health care, within educational programmes, that may or may not be validated by statutory bodies, or may be validated independently by each body.'
\end{abstract}

With the introduction of The NHS Plan (Department of Health (DH), 2000) the focus of care shifted further towards effective collaboration between agencies in the provision of health care. As a consequence the area of IPE has been reviewed (Barr, 2003) and one of the outcomes has been to explore IPE as a measure for improving the quality of care. Common learning was identified as a requirement for all pre- registration students by 2004 and it will eventually be integral within continuing professional education (DH, 2001a).

One of the main problems of IPE is the various titles given to it (Friend, 1997). Table 1 demonstrates the various terms cited in the literature. This in itself appears straight forward, however, the terms used are often dependent upon who is involved. The term 'training' was found to have negative connotations for some healthcare staff (Illingworth, 1999b). Why this might be was unclear, however, the health service has recently not generally employed trainers, whereas social services have. The reason could also be because some healthcare workers wish to become, or be seen to be, more 'professional'.

While this article focuses on the benefits of IPE for students undertaking healthcare training, it should be noted that any benefits for students should also impact on other stakeholders, namely service users, carers, service providers and higher education institutions (HEIs). The extent and value of IPE in health care is questionable. Any claim that IPE provides added value, offers a broader 
perspective to complement specialist professional expertise, and will make students more responsive to service user need, is, as yet, unproven.

\section{Partnership working}

The idea of professionals from various disciplines learning together is not new (Basset and Bryson, 1989). Indeed, the idea of collaborative working has an even longer history (Younghusband, 1959). The 1988 Griffiths Report (Her Majesty's Stationery Office (HMSO), 1988) highlighted the importance of collaboration and that if collaboration was to occur there would be a need for joint education programmes to be an essential part of any management plan (HMSO, 1998). In addition, legislation and policy requirements over the past decade required health and social care to work together in collaboration (Pearson and Spencer, 1995; Sainsbury Centre, 1997; DH, 1998a,b; Molyneux, 2001). Therefore, Hurst (1999) suggested a new educational model would be needed to meet future health care needs. Such a programme would be aimed at producing a multi-skilled workforce. The Health Service Management Unit (HSMU) (1996) had previously produced such a framework which had six elements:

- Common core modules for all health professionals

- Medical and science modules for some

- Generic modules for the majority of students

- Therapist modules for the majority of students

- Additional modules for generic carers or therapists working in areas such as intensive care units

- Continuing education modules for all health carers

The basic assumption behind these models was that the pooling together of expertise in teams would make them more effective and efficient and better care would follow. However, while this assumption may appear reasonable in theory, it was not always seen in practice (Ritchie, 1994; Farrell et al, 2001).

Research indicated that even though there was a wide belief that collaboration was good, there was little evidence that such collaboration enhanced the quality of care (Leathard, 1994).

Interprofessional conflict and professional and organizational boundaries, together with negative perceptions and prejudices of other professional groups/agencies, have been cited in the past as the main pitfalls in relation to collaboration (Ovretveit, 1990; McGrath, 1991). Many of these problems were more recently identified by Caldwell and Atwal (2003). Despite the difficulties, McGrath (1991) concluded, in a study into community mental health, that the advantages outweighed the disadvantages and that improved coordination of services resulted.

For most health professionals, their codes of practice state the need for practitioners to possess and demonstrate skills and attributes required for interprofessional working (Hewison and Sim, 1998). Many have argued that this would be best achieved through interprofessional education (Carpenter 1995; Carpenter and Hewstone, 1996). However, although Barr (2000a) stated that IPE could benefit health and social care professionals, he also cautioned that a sufficiently robust education and development strategy had yet to be devised to control the variables. Oxley (2002) researched shared learning and found a greater understanding of other professionals' roles and skills. Interprofessional teamwork skills began to be developed and their own professional identities were strengthened. Students were found to have greater awareness of diversity issues and gained 
both skills and knowledge regarding complex illnesses which required intervention from a range of professionals.

However, there was conflicting evidence with the above. Connor and Rees (1997), Pryce and Reeves (1997) and Freeth (2001) showed that IPE, especially pre-qualifying, was complicated. This was seen to be because of several factors: students' different prior educational experiences; levels of attainment and prior knowledge; incompatible curricula in terms of length, format and educational approach; professional requirements and the large numbers of students, unevenly split between professions. It is interesting to note that, even though service users and carers are central to current government policy, little work has been undertaken on the benefits that IPE has on the actual care received.

\section{Benefits for service users and carers}

There is scant evidence to suggest that progress has been made with regards to service user and carer involvement in educational programmes (DH, 2001b). Indeed, there appears to be little agreement as to what is expected of service users and carers when it comes to their involvement in course design, delivery and evaluation. Use of 'users expertise' should be made because of their comprehensive knowledge of how existing services really work, and the positive or negative impact users have in practice. There has been a predisposition to ignore or deny this expertise (Lowson, 1996). However, pleas have been made, often solitary, for service users to be acknowledged as experts and as such be involved in evidence-based practice (Illingworth, 1999a). Service users and carers should be included in the planning, delivery and evaluation of IPE (DH, 2001b). For without their 'expert opinion' professionals would not get a truly holistic view. Faulds Wood (2003) saw this expertise as a 'fantastic resource' and described how she challenged professionals to examine their practice and change colonoscopy training nationally.

Hopton (1994) had previously explored service user involvement in the education of mental health nurses. More recently, a National Continuous Quality Improvement Tool for Mental Helath Education (CCAWI, 2005), as well as a handbook and implementation guide (Brooker and Curran,2005) have been produced to assist in the development of post-qualifying mental health education. Integral to these is the involvement of service users and carers in the planning, delivery and evaluation of the educational provision.

\section{Benefits for service providers}

The need for an improved quality of service and the creation of a flexible workforce within the field of health care was described by Koppel (1998) and IPE can be seen as a major factor in achieving this improvement. Health needs are continually changing, and there is a need for health professionals to have the ability to adapt. Freeth et al (1998) listed the following as further benefits of IPE for health providers:

- A reduction in the occurrence of communications breakdowns

- An increase in morale and efficiency

- An avoidance of 'unhelpful protectionism'.

The final observation was one which has been frequently raised by user/patient groups (Lindow, $1991,1996)$. Health professionals generally follow their own discipline in pre- qualification 
education, and it is only after several years of training that they are exposed to other professions. This can mean that individual professional groups get into a narrow perspective.

Barr (2000a) maintained that, rather than perpetuate the situation described above, IPE will enhance personal and professional confidence, promote mutual understanding between professions, facilitate intra- and interprofessional communication and encourage reflective practice. However, little attention has been given to the accreditation of IPE and as such, no common value for it exists between professional groups (DH, 2001b).

The NHS Knowledge and Skills Framework (DH, 2004a) and its Agenda for Change process (DH, 2004b) will certainly assist in identifying service needs and means (staff with the correct skill mix) of addressing the need. This is seen as a way of developing individual staff with the appropriate knowledge and skills and as such, this is resulting in different professional groups are attending the same courses.

\section{Benefits for higher education institutions}

The move towards integration of professional education is a major trend in higher education and is in keeping with what Bernstein (1971) described as an 'integrated curriculum'. But this approach has not been the traditional approach to nurse education (Melia, 1987). However, Beattie (1995 p20) saw the integrated approach as having the distinct advantage of 'transcending the tribalism of health professionals'. Interprofessional education can also promote creativity in teaching and research and foster interprofessional cooperation (McCroskey and Robertson, 1999). It can also open up possibilities for practical application, for example, interprofessional project work.

A common thread throughout the literature generally, about the positive outcomes of IPE for institutions, was that of cost-effectiveness. Although the literature was clear, this was difficult to show (Koppel, 1998). Interprofessional education can, and should, lead to the development of the necessary skills to operate effectively in multidisciplinary teams. This will not automatically occur; however, without resources being currently used for direct teaching being transferred to teaching and learning support (Rance, 1996). As Rance $(1996, \mathrm{p} 8)$ concluded from evidence of such initiatives at the University of Central England:

'To bring students together from different pro- fessional degrees for the sake of commonality is unlikely to produce a satisfactory educational experience without a clear sense of the inter- professional objectives of such an arrangement.'

However, feedback from faculty in McCroskey and Robertson's (1999) evaluation of the University of California's interprofessional initiative indicated that there were clear benefits for individual staff members:

- Exposure to new ideas

- Opportunity to work with different people

- Increased cultural sensitivity

- Enhanced flexibility in working with students

- Improved sense of co-operation and networking between departments

- Impetus to discover more community resources. 


\section{Benefits for students}

Health professionals' training is, for the most part, insular in both approach and content (Illingworth, 1999b). It has been argued that such insular training can '....undermine effective inter-disciplinary working...' (George, 1996 p20). From the perspective of social work and health, O'Neill et al (2000) argued that meaningful IPE experiences can better prepare students for encountering the complexities of real-life interprofessional work-based problems. These experiences help develop a holistic approach to working, based on a common knowledge between disciplines and an appreciation of diversity issues.

IPE can help students recognize the overlapping professional functions, or those activities which fall between professional roles. IPE could initiate a breaking down of professional roles within the socialization process, which could otherwise lead to competition and conflict. An environment in which students could develop a critical awareness of the limitations of professional roles and values would then ensue.

IPE works to challenge stereotypes, yet allows students to strengthen their own professional identities (McCroskey and Robertson, 1999; O'Neill et al, 2000). O'Neill et al (2000) further illustrated this from preliminary evaluations of an interprofessional course. Students on the course gained a greater understanding of other professions' roles and skills and began developing skills in interprofessional teamwork. They also gained knowledge and skills in relation to complex conditions that required multiprofessional intervention. McCroskey and Robertson (1999) identified learning and increased use of similar skills, and especially recognized the development of interpersonal skills.

IPE engenders a respect for, and understanding of, the role of other associated professions (McCroskey and Robertson, 1999); interprofessional teaching contributes to this by giving students the opportunity to observe good role models for collaboration, with different faculty/departmental members interacting as peers.

\section{Discussion}

It was clear from the literature reviewed, that there is support for IPE initiatives within higher education, and that IPE can bring benefits. However, there were reservations about how successful such initiatives could be. O'Neill et al (2000) identified several problems which included finding suitable placements, motivations for taking the course, and preferred learning styles. Other issues included whether students transferred the knowledge and skills gained by learning interprofessionally within the classroom setting to the practice environment and how this could be effectively evaluated.

Developing mechanisms for measuring the effectiveness of IPE is complex and time consuming. There is a dearth of research-based evidence to support the idea of IPE. However, there are activities and behaviour changes which reflect improved client care (Barr and Shaw, 1994; Zwarenstein et al, 1998) Additionally Roberts (1998 p21), when looking at mental health, asserted the 'benefits of localized initiatives in terms of positive working relationships and shared understanding can only enhance health care'.

This belief that IPE enhances health care, is the main reason given for pursuing it. From the literature, the benefits most frequently cited were identified by Connor and Rees (1997): 
- Increased understanding of the roles and skills of other professionals and improved respect between professional groups

- The building of interprofessional networks

- More effective liaison

- A wider perspective with improved communication and potentially a 'shared language'

- Alliances between professional groups leading to greater influence

- Greater cost-efficiency in the delivery of education.

Barr et al (2000b) summarized the four main benefits that IPE could provide which he saw as enhanced motivation to collaborate, changed attitudes and perceptions; cultivated interpersonal, group and organizational relations and established common value and knowledge bases

\section{Conclusions}

How HEls and health providers can work to develop the various positive outcomes of IPE described above has yet to be seen. However, by encouraging the sharing of learning and teaching issues between academic staff from different disciplines and HEls, interprofessional education will not only be developed, but will be seen to be happening.

Barriers to IPE are breaking down. The more professionals share, the more they are likely to learn. The more barriers they cross, the more useful their ideas will be. Such free, focused, voluntary, open-ended behaviour will become more valuable in what has already become an increasingly knowledge-based society.

Until such time as empirical evidence exists to demonstrate that service users and carers are benefiting from IPE, all partners in the process should not simply follow a single IPE route. Clarity as to what is expected of service users (and carers) regarding their contribution to curriculum design, delivery and evaluation is required. Perhaps as important is the need to demonstrate that service users and carers are benefiting from IPE. Clearly the need for research to ascertain the effectiveness of IPE in direct relation to service user and carer outcome is needed, as is the implications for curriculum planning, education, training and practice.

\section{References}

Barr H (2003) Assuring the Quality of Interprofessional Education for Health and Social Care. CAIPE Bulletin 22

Barr H (2000a) Interprofessional Education: 1997-2000. A Review. United Kingdom Central Council of Nursing, Midwifery and Health Visiting, London

Barr H, Freeth D, Hammick M, Koppel I, Reeves S (2000b) Evaluations of Interprofessional Education:A United Kingdom Review for Health and Social Care. Review. UK Center for the Advancement of Interprofessional Education/ British Educational Research Association, London

Barr H, Shaw I (1994) Shared Learning: Selected Examples From The Literature.CAIPE, London

Basset T, Bryson T (1989) A bridge to learning. Health Serv J 99: 1246-7 
Beattie A (1995) War and Peace Among the Health Tribes. In: Soothill K, Mackay L, Webb C eds. Interprofessional Relations in Health Care. Edward Arnold, London

Bernstein B (1971) Class, Codes and Control. Vol 1. Routledge, London

Brooker C, Curran J (2005) National Continuous Quality ImprovementTool for Mental Health Education. Handbook and Implementation Guide. Centre for Clinical and Academic Workforce Innovation, University of Lincoln, Mansfield

Caldwell K, Atwal A (2003) The problems of interprofessional healthcare practice in hospitals. $\mathrm{Br} J$ Nurs 12(20): 1212-18

Carpenter J (1995) Interprofessional education for medical and nursing students: evaluation of a programme. Med Educ 29: 265-72

Carpenter J, Hewstone M (1996) Shared learning for doctors and social workers. Br J Soc Work 26: 239-57

CCAWI (2005) National Continuous Quality Improvement Tool for Mental Health Education. 2nd edn. Centre for Clinical and Academic Workforce Innovation, University of Lincoln, Mansfield

Connor C, Rees S (1997) Ways forward for shared learning between nursing and social work students. Nurse Educ Today 17: 494-501

Department of Health (1998a) A First Class Service: Quality in the NHS. HMSO, London Department of Health (1998b) Partnership in Action. (New opportunities for joint working between Health and Social Services). A discussion document. HMSO, London.

Department of Health (2000) The NHS Plan. A Plan for Investment, A Plan for Reform. Available: www.dh.gov.uk/assetRoot/04/05/57/83/04055783.pdf. Accessed 10 January 2007

Department of Health (2001a) Working Together, Learning Together. HMSO, London

Department of Health (2001b) Mental Health National Service Framework (and NHS Plan):Workforce Planning, Education and Training Underpinning Programme: Adult Mental Health Services: Final Report Final Report by the Workforce Action Team. DH, London

Department of Health (2004a) The NHS Knowledge and Skills Framework (NHS KSF) and the Development Review Process. HMSO, London

Department of Health (2004b) Agenda for Change. Final Agreement. HMSO, London Farrell MP, Schmitt MH, Heinemann GD (2001) Informal roles and the stages of interdisciplinary team development. J Interprof Care 15(3): 281-95

Faulds-Wood L (2003) Bringing in the experts. Health Management April: 10-11

Freeth D, Meyer J, Reeves S, Spilsbury K (1998) Of Drops in the Ocean and Stalactites: Interprofessional Education Within Healthcare Settings. BERA, Queen's University, Belfast 
Freeth D (2001) Sustaining interprofessional collaboration. J Interprof Care 15(1): 37-46

Friend B (1997) Two heads. Health Serv J 107: 19-20

George M (1996) Rebuilding for safety. Community Care 1145: 20-1

Harding T (1991) Sharing Differences Towards Common Practices. Bristol Polytechnics/Avon College of Health, England

Hewison A, Sim J (1998) Managing interprofessional working: using codes of ethics as a foundation. J Interprof Care 12: 309-12

Hopton J (1994) User involvement in the education of mental health nurses.An evaluation of possibilities. Critical Social Care 14(3): 47-60

HMSO (1988) (The Griffiths Report) Community Care Agenda for Action. HMSO, London Health Service Management Unit (1996) The Future Healthcare Workforce. HSMU, Manchester Hurst K (1999) Educational implications of multiskilled health carers. MedTeach 21: 170-3 Illingworth P (1999a) Return to sender. Nurs Times 95(38): 27-8

Illingworth P (1999b) Review of the Development and Implementation of a Joint Training Strategy, Mental Heath. University of Hertfordshire, Hatfield

Koppel I (1998) Evaluation of Interprofessional Education: State of Art:The IPE JET Study. BERA, Queen's University, Belfast

Leathard A (ed) (1994) Going Inter-professional. Working Together for Health \& Welfare. Routledge, London

Lindow V (1991) Experts, lies and stereotypes. Health Serv J 101(5267): 18-19

Lindow V (1996) Presentation: Developing Empowering Services in Practice. Direct Power Conference. UMIST, Manchester

Lowson D (1996) User Involvement And Issues ForWorkers - Promoting User Involvement (Self Advocacy) In Mental Health - An Overview Of Options. MIND, Wales

McCroskey J, Robertson PJ (1999) Challenges and Benefits of Interprofessional Education: Evaluation of the Inter-Professional Initiative at the University of Southern California. Teacher Education Quarterly (Fall): 69-87

McGrath M (1991) Multiprofessional Teamwork. Avebury, Aldershot

Melia K (1987) Learning and Working. The Occupational Socialization of Nurses. Tavistock, London Molyneux J (2001) Interprofessional teamworking: what makes teams work well? J Interprof Care 15(1): 29-35 
Oxley A (2002) BetterTogether.Inter-Professional Collaboration:Simulating Partnership Working in the Built Environment. Occassional Paper 2. Interprofessional Practice in Health: Lessons for the Built Environment. Sheffield Hallam University

Ovretveit J (1990) Co-operation in Primary Health Care. Brunel Institute of Organisation and Social Studies, Uxbridge

Pearson P, Spencer J (1995) Pointers to effective teamworking: exploring primary care. J Interprof Care 9: 131-8

Pryce A, Reeves S (1997) An exploratory evaluation of an inter-professional education model for medical, dental and nursing students: final report for the Department of Health. City University, London

Rance B (ed) (1996) Proceedings of a Conference on Interprofessional Education and Large Group Teaching in the Built Environment. University of Central England, Birmingham

Ritchie JH (1994) The Report of the Inquiry into the Care and Management of Christopher Clunis. HMSO, London

Roberts P (1998) Shared Learning in Mental Health Education. CAIPE Bulletin. No15 Autumn. pp20-1. CAIPE, London

Sainsbury Centre (1997) Pulling Together.The Future Roles and Training of Mental Health Staff. Sainsbury Centre for Mental Health, London

Younghusband E (1959) Report of the Working Party on Social Workers in the Local Authority, Health and Welfare Services. HMSO, London

Zwarenstein M, Bryant W, Baillie R, Sibthorpe B (1997) Interventions to change collaboration between nurses and doctors. (Cochrane Review) The Cochrane Library. Issue 3 Oxford Update

Table 1. Terms used to describe IPE

- Joint training

- Shared learning

- Interagency education

- Interagency training

- Interprofessional education

- Interprofessional training

- Multiagency training

- Multidisciplinary training

- Multidisciplinary education

- Multiprofessional education

- Multiprofessional training

- 